\title{
Fatigue Design and Defects in Metals and Alloys
}

\author{
Vigilio Fontanari * and Matteo Benedetti \\ Department of Industrial Engineering, University of Trento, 38123 Trento, Italy; matteo.benedetti@unitn.it \\ * Correspondence: vigilio.fontanari@unitn.it; Tel.: +39-0461-282430
}

Received: 16 June 2020; Accepted: 28 June 2020; Published: 29 June 2020

check for updates

\section{Introduction and Scope}

The effort to correctly understand and account for the detrimental influence of defects in the design of components undergoing in service complex time-varying loads characterizes the major part of the history of metal fatigue. The reduction of the defect's criticality, as well as the ability to account for their presence to predict the fatigue properties and service life of components, represent key factors for the successful application of any manufacturing process, from mature (e.g., casting) to emerging technologies (e.g., additive manufacturing). The development of specific treatments for improving the tolerance for defects of structural parts (e.g., surface treatments) is also of great interest in the scientific and technical communities. A deep knowledge of these aspects is of great importance in view of the even more widespread fatigue packages in computer-aided-design (CAD) software: The proficient implementation of defect tolerant design criteria would be very important to avoid the unsafe design of components. Moreover, it would also be very helpful in the correct definition of health monitoring strategies. This Special Issue scope embraces experimental, theoretical and numerical studies aimed at incorporating the research outcomes into design approaches for the fatigue assessment of structural components and mechanical parts. The published papers report recent advances in the fatigue of metals and components with a special emphasis on the influence of different types of defects, from micro to macro scales, in the different fatigue regimes and on the methods developed to account for them in the design of components.

\section{Contributions}

Twelve research articles have been published in this Special Issue of Metals. The subjects are multidisciplinary, including (i) the effect of microstructural defects on the high and very high cycle fatigue strength of metallic materials [1-5], (ii) probabilistic fatigue prognosis incorporating the size of defects and control volume [2,4,6], (iii) the effects of plasticity, high temperature, and aggressive environment on the fatigue response [7-9], (iv) thermo-chemo-mechanical treatments to mitigate the detrimental effect of defects on the fatigue strength $[10,11]$, and (v) non-destructive techniques to detect fatigue critical defects [12].

First, five articles deal with the effect of microstructural defects on the high and very high cycle fatigue strength of metallic materials. Bertini et al. [1] investigated static and fatigue properties of a wrought spinodally hardened $\mathrm{Cu}-15 \mathrm{Ni}-8 \mathrm{Sn}$ cast alloy under two distinct delivery conditions. They found that the material variant affected by pronounced inhomogeneous grain size distribution displays the lower fatigue strength, while the tensile properties are much less influenced. Deng et al. [2] examined the fatigue failure of carburized $12 \mathrm{Cr} 2 \mathrm{Ni}$ alloy steel until fatigue lives of $10^{8}$ cycles. They found a progressive shift from surface to sub-superficial crack initiation in the vicinity of oxide inclusions. The size of the critical defect triggering the fatigue damage was found to increase with increasing volume of critically stressed material. Tridello [3] explored the giga-cycle fatigue regime of two variants of $\mathrm{H} 13$ tool steel using an ultrasonic fatigue testing apparatus and two different types of specimen geometry. He found that all the fatigue failures originated from internal inclusions. 
The critical inclusion population was the same in both $\mathrm{H} 13$ steel variants and globular inclusions were the most critical and the most frequent defects. The critical inclusions were significantly larger in Gaussian specimens than those in hourglass specimens. Fontanari et al. [4] investigated the tooth root bending fatigue strength of small-module gears fabricated via powder metallurgy. They found that the fatigue strength is the result of a complex interplay between porosity and microstructure, as the former factor essentially depends on the size and shape of the critical pore leading to crack initiation, the latter is related to the microhardness of the softest microstructural constituent surrounding the critical defect. Schäfer et al. [5] researched the fatigue crack nucleation behavior of the martensitic steel SAE 4150 at different microstructural defects by means of micromechanical simulations. They highlighted the important role played by size and shape of oxide inclusions, martensitic block size and the crystallographic properties on the local fatigue crack nucleation response.

Second, probabilistic fatigue prognosis methods are discussed in three papers. Sun and Song [6] devised a probabilistic control volume method for correlating the effects of specimen geometry and loading condition on the fatigue strength based on Weibull distribution and the concept of control volume. They were able to rationalize the fatigue data collected on plain and notched samples made of Ti-6Al-4V alloy. Tridello [4] analyzed the fatigue data using marginal (not conditioned to the inclusion size) P-S-N curves. Deng et al. [2] used the generalized extreme values (GEV) distribution to estimate the maximum defect size.

Third, three papers dealt with plasticity and environmental effects on the fatigue damage. Hwang at al. [7] investigated the corrosion-fatigue behavior of welded joints between dissimilar steels. They attributed the lowest fatigue strength displayed by the joints in saline solution than in air to environmentally assisted crack propagation. Wang et al. [8] studied the interaction between low-cycle fatigue and creep fatigue in high Cr-steels. They devised a damage model encapsulating temperature, frequency (viz. strain rate), elastic and plastic strain to interpret the experimental results. Algarni et al. [9] investigated the effect of plastic damage accumulation on the extremely low-cycle fatigue of Inconel 718 alloy. They found that the ductile fracture mechanism takes the dominant role in very high strain cycling loading. Therefore, the fracture surfaces denoted microvoid nucleation, growth, and coalescence with no sign of striations.

Fourth, two papers investigated thermo-chemo-mechanical treatments aimed at reducing the detrimental effect of defects on the fatigue strength. Zhao et al. [10] evaluated the effect of shot peening on the fatigue strength of notched specimens of 40Cr steel. The defect is in this case the process-induced surface roughening, whose detrimental effect is overweighed by compressive residual stresses and work hardening. Campagnolo et al. [11] researched the effect of nitrocarburizing and post-oxidation of the plain and fatigue strength of a low carbon steel. They found that the surface compressive residual stress field pushes crack initiation below the treated in plain samples. On the contrary, the stress concentration induced by the notch causes the crack to initiate at the notch tip, which is embedded in a surface porous layer produced by the thermo-chemical treatment. In any case, the fatigue strength was higher than that of the untreated counterpart.

Finally, Zhang et al. [12] proposed an autocorrelation subtraction approach to enhance the defect detection sensitivity of an ultrasonic waved array technique. Experimental validation tests demonstrated that the proposed method can greatly improve the signal to noise ratio and permits the correct identification of artificially introduced defects. This can pave the way for future applications of the method to detecting real defects as those analyzed in the present Special Issue.

\section{Conclusions and Outlook}

The present Special Issue of Metals provided a wide and comprehensive insight into the current state of the research on defect-related aspects of fatigue analysis, testing and synthesis. We are confident that this special issue will be a valuable starting point for future discussions and scientific debate on challenging topics related to fatigue damage and fatigue design. The published articles will stimulate further research on defect characterization, detection and incorporation into fatigue prognosis methods. 
As guest editors of this special issue, we are very happy with the final result, and hope that the present papers will be useful to researchers, designers, and practitioners working towards the demanding objective of failure prevention in the unavoidable presence of the defects, especially with the advent of additive manufacturing and process-related defectiveness. We would like to express our deep gratitude to all the authors for their contributions as well as to the anonymous reviewers for their efforts in ensuring a high-quality publication. Sincere thanks also to editors of Metals for their continuous help, and to the editorial assistants of Metals for their valuable and inexhaustible engagement and support during the preparation of this special issue. In particular, our sincere gratefulness to Ms. Betty Jin for her help and encouragement.

Conflicts of Interest: The authors declare no conflict of interest.

\section{References}

1. Bertini, L.; Bucchi, F.; Frendo, F.; Valentini, R. Microstructure and Fatigue Behavior of a Ni-Cu-Sn Alloy. Metals 2018, 8, 888. [CrossRef]

2. Deng, H.; Liu, Q.; Liu, H.; Yu, H. Long-Life Fatigue of Carburized 12Cr2Ni Alloy Steel: Evaluation of Failure Characteristic and Prediction of Fatigue Strength. Metals 2018, 8, 1006. [CrossRef]

3. Tridello, A. VHCF Response of Two AISI H13 Steels: Effect of Manufacturing Process and Size-Effect. Metals 2019, 9, 133. [CrossRef]

4. Fontanari, V.; Molinari, A.; Marini, M.; Pahl, W.; Benedetti, M. Tooth Root Bending Fatigue Strength of High-Density Sintered Small-Module Spur Gears: The Effect of Porosity and Microstructure. Metals 2019, 9, 599. [CrossRef]

5. Schäfer, B.J.; Sonnweber-Ribic, P.; ul Hassan, H.; Hartmaier, A. Micromechanical Modeling of Fatigue Crack Nucleation around Non-Metallic Inclusions in Martensitic High-Strength Steels. Metals 2019, 9, 1258. [CrossRef]

6. Sun, C.; Song, Q. A Method for Predicting the Effects of Specimen Geometry and Loading Condition on Fatigue Strength. Metals 2018, 8, 811. [CrossRef]

7. Hwang, J.H.; Lee, J.H.; Ahmad, H.W.; Ha, S.W.; Bae, D.H.; Kebede, H.Y. Assessing Corrosion Fatigue Characteristics of Dissimilar Material Weld between Alloy617 and 12Cr Steel Using Buttering Welding Technique. Metals 2018, 8, 826. [CrossRef]

8. Wang, X.; Zhang, W.; Zhang, T.; Gong, J.; Wahab, M.A. A New Empirical Life Prediction Model for 9-12\%Cr Steels under Low Cycle Fatigue and Creep Fatigue Interaction Loadings. Metals 2019, 9, 183. [CrossRef]

9. Algarni, M.; Bai, Y.; Zwawi, M.; Ghazali, S. Damage Evolution Due to Extremely Low-Cycle Fatigue for Inconel 718 Alloy. Metals 2019, 9, 1109. [CrossRef]

10. Zhao, X.; Sun, Z.; Xu, D.; Liu, Y. Local Fatigue Strength Evaluation of Shot Peened 40Cr Notched Steel. Metals 2018, 8, 681. [CrossRef]

11. Campagnolo, A.; Dabalà, M.; Meneghetti, G. Effect of Salt Bath Nitrocarburizing and Post-Oxidation on Static and Fatigue Behaviours of a Construction Steel. Metals 2019, 9, 1306. [CrossRef]

12. Zhang, H.; Zhang, J.; Fan, G.; Zhang, H.; Zhu, W.; Zhu, Q.; Zheng, R. The Auto-Correlation of Ultrasonic Lamb Wave Phased Array Data for Damage Detection. Metals 2019, 9, 666. [CrossRef] 